\title{
Polymerization-Induced Hierarchical Electrostatic Self-Assembly: Scalable Synthesis of Multicompartment Polyion Complex Micelles and their
}

Monolayer Colloidal Nanosheets and Nanocages

Qizhou Liu, Xiyu Wang, Lei Ma, Kaiwen Yu, Weixing Xiong, Xinhua Lu, and Yuanli Cai*

\section{Supporting Information}

Materials. Histamine acrylamide hydrochloride ${ }^{1}$ (HisAM) monomer, sodium phenyl-2,4,6-trimethylbenzoylphosphinate ${ }^{2}$ (SPTP) photo-initiator, and 4-cyano-4-ethylsulfanylthiocarbonylsulfanylpentanoic $\operatorname{acid}^{3}(\mathrm{CEP})$ chain transfer agent were synthesized according to literature procedures. Poly(N-2-hydroxypropylmethacrylamide) chain transfer agent (PHPMA 65 macro-CTA; ${ }^{1} \mathrm{H}$ NMR: $\mathrm{DP}=65 ;$ SEC: $\left.\mathrm{M}_{\mathrm{n}}=9.5 \mathrm{kDa}, \nexists=1.19\right)$ was synthesized by visible light-initiated RAFT aqueous solution polymerization. ${ }^{4}$ Diacetone acrylamide (DAAM) monomer was donated by Hipro Polym. Mater. Company, recrystallized prior to use. 2-Acrylamido-2-methylpropanesulfonic acid (AMPS) monomer was purchased from Sigma-Aldrich; deuterium oxide $\left(\mathrm{D}_{2} \mathrm{O}, 99.8 \% \mathrm{D}\right)$ and $\mathrm{DCl}(20 \%$ in $\mathrm{D}_{2} \mathrm{O}, 99.5 \% \mathrm{D}$ ) from J\&K; other reagents from Aladdin; these reagents were used as received. The deionized water was obtained from a Direct-Q 5 UV Millipore system, and used for the synthesis and characterization.

Synthesis of PAMPS-PDAAM Anionic Micelles. First we synthesized anionic PAMPS macroCTA as follows. AMPS monomer (47.5\% w/w in water, $12.0 \mathrm{~g} ; 52.4 \mathrm{mmol})$ and CEP chain transfer agent $(91.8 \mathrm{mg}$ in $5.73 \mathrm{~g}$ methanol; $0.35 \mathrm{mmol})$ were added into a $25 \mathrm{~mL}$ flask. SPTP initiator (27.0 mg, $87.2 \mu \mathrm{mol})$ was added into the flask in the dark. The flask was sealed, immersed into a 
water bath at $25^{\circ} \mathrm{C}$ and bubbled with argon gas for $45 \mathrm{~min}$. The solution was irradiated with visible light for $2 \mathrm{~h}$. The reaction was quenched by exposure to air. ${ }^{1} \mathrm{H}$ NMR: $>99 \%$ conv. The solution was dialyzed against water using dialysis membrane $(\mathrm{MWCO}=1.0 \mathrm{kDa})$ and freeze-dried to afford a light yellow product. Yield: $11.3 \mathrm{~g}, 94 \% .{ }^{1} \mathrm{H}$ NMR: $\mathrm{DP}=150$, PAMPS 150 macro-CTA; SEC: $\mathrm{M}_{\mathrm{n}}$ $=34.3 \mathrm{kDa}, \oslash=1.12$. To examine the fidelity of RAFT end-groups, chain extension was conducted at $[\mathrm{AMPS}]_{0} /\left[\mathrm{PAMPS}_{150}\right]_{0} /[\mathrm{SPTP}]_{0}=500: 1: 0.20$ at $50 \% \mathrm{w} / \mathrm{w}$ solids in water under visible light irradiation at $25^{\circ} \mathrm{C}$ for $1 \mathrm{~h}$.

$\mathrm{A}_{150} \mathrm{~B}_{70}$ anionic micelles $\left(\mathrm{A}=\mathrm{PAMPS}, \mathrm{B}=\right.$ PDAAM) were synthesized as follows. PAMPS $\mathrm{S}_{150}$ macro-CTA $(3.0 \mathrm{~g}, 87.3 \mu \mathrm{mol})$ and DAAM monomer $(1.03 \mathrm{~g}, 6.11 \mathrm{mmol})$ were dissolved in water $(4.10 \mathrm{~g})$ in a $25 \mathrm{~mL}$ flask. SPTP initiator $(1.0 \% \mathrm{w} / \mathrm{w}$ in water, $7.4 \mathrm{mg} ; 24.0 \mu \mathrm{mol})$ was added into the flask in the dark. The flask was sealed, immersed into a water bath at $25{ }^{\circ} \mathrm{C}$, and bubbled with argon for $45 \mathrm{~min}$. The solution was irradiated with visible light for $2 \mathrm{~h}$. The reaction was quenched by exposure to air to afford the anionic $\mathrm{A}_{150} \mathrm{~B}_{70}$ micelles. ${ }^{1} \mathrm{H}$ NMR: $>99 \%$ conv. RAFT chain-ends was removed by $\mathrm{H}_{2} \mathrm{O}_{2}$ oxidation reaction. ${ }^{5} \mathrm{H}_{2} \mathrm{O}_{2}(30 \% \mathrm{w} / \mathrm{w}$ in water, $0.394 \mathrm{~g} ; 3.49 \mathrm{mmol})$ was added into dispersion $(25 \% \mathrm{w} / \mathrm{w}, 0.116 \mathrm{mmol}$ TTC end-groups) in a $100 \mathrm{~mL}$ flask. The flask was immersed into an oil bath at $80^{\circ} \mathrm{C}$, and stirred overnight. The final dispersion was dialyzed against water in a membrane $(\mathrm{MWCO}=50 \mathrm{kDa})$ and freeze-dried to afford final anionic micelles. Yield: $3.8 \mathrm{~g}, 94 \%$. The removal of RAFT chain-ends was confirmed using UV-vis spectroscopy and the absence of thiol impurities was evidenced using Ellman method. ${ }^{6} \mathrm{~A}_{150} \mathrm{~B}_{100}$ and $\mathrm{A}_{150} \mathrm{~B}_{150}$ anionic micelles were synthesized under the above conditions at $[\mathrm{DAAM}]_{0} /\left[\mathrm{PAMPS}_{150}\right]_{0}=100$ or 150 . The anionic micelles were studied using ${ }^{1} \mathrm{H}$ NMR, $\zeta$-potential, DLS, TEM and AFM.

Hierarchical PIESA using A A50B 70 Anionic Micelles. Typically, HisAM monomer (62.4 mg, $0.38 \mathrm{mmol}$ ), $\mathrm{A}_{150} \mathrm{~B}_{70}(116.4 \mathrm{mg}, 0.38 \mathrm{mmol}$ PAMPS units), and PHPMA 65 macro-CTA (18.1 mg, 
$1.89 \mu \mathrm{mol})$ were dissolved in water $(0.58 \mathrm{~g})$ in a $5 \mathrm{~mL}$ flask. The solution was adjusted to $\mathrm{pH} 2.5$. SPTP initiator ( $1 \% \mathrm{w} / \mathrm{w}$ in water, $19.5 \mathrm{mg} ; 0.63 \mu \mathrm{mol})$ was added. The flask was sealed, immersed in a water bath at $25^{\circ} \mathrm{C}$ and bubbled with argon gas for $1 \mathrm{~h}$. The mixture was irradiated with visible light for $6 \mathrm{~h}$. The reaction was quenched by exposure to air. The dispersion was studied without purification. ${ }^{1} \mathrm{H}$ NMR: $>99 \%$ conv., $\mathrm{A}_{150} \mathrm{~B}_{70} / \mathrm{C}_{65} \mathrm{D}_{200}$ PICs (C = PHPMA, D = PHisAM); SEC: $\mathrm{M}_{\mathrm{n}}$ $=59.2 \mathrm{kDa}, \oslash=1.19$ for $\mathrm{C}_{65} \mathrm{D}_{200}$ diblock copolymer. $\mathrm{A}_{150} \mathrm{~B}_{70} / \mathrm{C}_{65} \mathrm{D}_{m}$ PICs $(m=100,130,150,170)$ were synthesized changing $m$ ([HisAM $\left.]_{0} /\left[\mathrm{PHPMA}_{65}\right]_{0}\right)$. Aqueous properties and nanostructures were studied using $\zeta$-potential, DLS, TEM and AFM. Effect of anionic micelles on the structural hierarchy was studied by analyzing nanostructured PICs synthesized via hierarchical PIESA using $\mathrm{A}_{150} \mathrm{~B}_{100}$ or $\mathrm{A}_{150} \mathrm{~B}_{150}$ anionic micelles.

Kinetics of Hierarchical PIESA. The kinetics of hierarchical PIESA at $m=200$ was studied as follows. HisAM monomer $(0.62 \mathrm{~g}, 3.83 \mathrm{mmol}), \mathrm{A}_{150} \mathrm{~B}_{70}$ anionic micelles $(1.16 \mathrm{~g}, 3.83 \mathrm{mmol}$ PAMPS units) and PHPMA 65 macro-CTA $(0.18 \mathrm{~g}, 18.9 \mu \mathrm{mol})$ were dispersed in water $(5.86 \mathrm{~g})$ in a $20 \mathrm{~mL}$ flask in a $5 \mathrm{~mL}$ flask. The solution was adjusted to $\mathrm{pH} 2.5$. SPTP initiator (1.0\% in water, $0.19 \mathrm{~g}, 6.3 \mu \mathrm{mol}$ ) was added into the flask. The flask was sealed, immersed in a water bath at $25^{\circ} \mathrm{C}$, and bubbled with argon in the dark for $1 \mathrm{~h}$. The mixture was irradiated with visible light. Aliquot was withdrawn at predetermined time. The reaction was quenched by exposure to air. The kinetics and structural evolution were studied using ${ }^{1} \mathrm{H}$ NMR, DMF SEC, $\zeta$-potential, DLS, and TEM.

Instrumentation. Incident visible light $\left(\mathrm{I}_{420 \mathrm{~nm}}=0.20 \mathrm{~mW} / \mathrm{cm}^{2}\right)$ was obtained from a homemade system equipped with mercury lamp, JB400 filter, UV-A radiometer, and ventilator. Polymer product was freeze-dried in a Labconco Freezone $2.5 \mathrm{~L}$ freeze-drier. The $\mathrm{pH}$ value was determined using an OHAUS ST3100 digital pH-meter. 
Characterization. UV-Vis Spectroscopy was conducted on a Shimadzu UV-3600 spectrometer. ${ }^{1} H$ NMR Spectroscopy was performed on an INOVA $400 \mathrm{MHz}$ NMR instrument. Aqueous Size Exclusion Chromatography (aqueous SEC) was performed on a Waters1515 GPC instrument equipped with a refractive index detector and a column set $(2 \times$ PL Aquagel-OH Mixed-M $)$ using degassed buffer eluent $\left(0.20 \mathrm{M} \mathrm{NaNO}_{3}, 0.01 \mathrm{M} \mathrm{Na}_{2} \mathrm{HPO}_{4}, \mathrm{pH} 9.0\right)$ and polyethylene oxide (PEO) calibration standards (Agilent, $17.8-692.0 \mathrm{kDa}$ ). The calibration and analysis were conducted at a $1.0 \mathrm{~mL} / \mathrm{min}$ flow rate at $30{ }^{\circ} \mathrm{C}$. The reaction solution was diluted into buffer to $2.0 \mathrm{mg} / \mathrm{mL}$ and passed through a $0.2 \mu \mathrm{m}$ Supor filter prior to aqueous SEC studies. DMF SEC was conducted on a PL-GPC220 integrated system equipped with a refractive index detector and a PL-GPC column set $(2 \times$ PLGel MIXED-B + $1 \times$ PLGel MIXED-D). DMF containing $10.0 \mathrm{mM} \mathrm{LiBr}$ was used as the eluent. Poly(methyl methacrylate) standards (Agilent, 1.95 - $1048 \mathrm{kDa}$ ) was used for calibration. Calibration and analysis were conducted at a flow rate of $1.0 \mathrm{~mL} / \mathrm{min}$ at $80^{\circ} \mathrm{C}$. The final dispersion was freeze-dried. The solids ( $43.9 \mu \mathrm{mol}$ imidazolic groups) were dispersed in $3 \mathrm{~mL}$ methanol. The dispersion was changed to transparent solution by the deprotonation of imidazolium groups using triethylamine (5.0 equiv. to imidazole groups). Di-tert-butyldicarbonate (5.0 equiv.) and tributylphosphine (1.0 equiv.) were added into the solution and stirred overnight. After passing through a silica column to remove anionic micelles and ammonium salt and rotary evaporation to remove solvent, the copolymer was dissolved in $3.0 \mathrm{~mL}$ DMF. The solution was filtered using a $0.2 \mu \mathrm{m}$ PTFE filter prior to DMF SEC studies. Zeta Potential ( $\zeta$ ) was determined on a Malvern Zetasizer Nano-ZS90 instrument. Dynamic Light Scattering (DLS) was performed on a Brookhaven BI200SM instrument equipped with $22 \mathrm{~mW}$ He-Ne laser $(\lambda=633 \mathrm{~nm})$, BI-200SM goniometer and BI-Turbo-Corr digital correlator. Sample cell kept at $25^{\circ} \mathrm{C}$ using a BI-TCD controller. The sample was measured at $90^{\circ}$ or otherwise mentioned. The intensity-average hydrodynamic diameter $\left(\mathrm{D}_{\mathrm{h}}\right)$ 
and particle size distribution (PDI) were obtained using cumulants analysis in CONTIN routine. Data were averaged over 5 runs. Transmission Electron Microscopy (TEM) was performed on a Hitachi HT7700 transmission electron microscope. The dispersion was diluted to $1.0 \mathrm{mg} / \mathrm{mL}$ using cold water $\left(0^{\circ} \mathrm{C}, \mathrm{pH} 2.5\right)$. An aliquot $(10 \mu \mathrm{L})$ was dropped onto a carbon-film copper grid, frozen to $-170{ }^{\circ} \mathrm{C}$ in liquid nitrogen in a home-made cryo-box and freeze-dried under reduced pressure prior to the TEM studies. The mean diameter $\left(D_{n}\right)$ of spheres was evaluated by statistical analysis from >300 spheres using NanoMeasurer 1.2 software. Atomic Force Microscopy (AFM) was conducted on a Bruker Multimode 8 microscope operated in a peak force quantitative nanomechanical mode. Silicon wafer was immersed into piranha solution at $80{ }^{\circ} \mathrm{C}$ for $1.5 \mathrm{~h}$, rinsed with water, ethanol, acetone, ethanol and water under ultrasonic agitation. The dispersion was diluted to $0.2 \mathrm{mg} / \mathrm{mL}$ in water $\left(0^{\circ} \mathrm{C}, \mathrm{pH} 2.5\right)$. Aliquot $(10 \mu \mathrm{L})$ was dropped on a clean silica wafer, frozen to $-170{ }^{\circ} \mathrm{C}$ in liquid nitrogen and freeze-dried under reduced pressure prior to AFM studies. 
Table S1. Structural Parameters of Preassembled Anionic $\mathrm{A}_{150} \mathrm{~B}_{\mathrm{p}}$ Diblock Copolymer Micelles

\begin{tabular}{|c|c|c|c|c|c|c|c|}
\hline Composition $^{[\mathrm{a}]}$ & $\begin{array}{l}M_{n}^{[b]} \\
(k D a)\end{array}$ & $\begin{array}{l}\zeta^{[\mathrm{c}]} \\
(\mathrm{mV})\end{array}$ & $\begin{array}{l}D_{h^{[d]}}^{[d} \\
(n m)\end{array}$ & PDI $I^{[\mathbf{d}]}$ & $\begin{array}{l}D_{\mathbf{n}^{[e]}} \\
(\mathrm{nm})\end{array}$ & $\begin{array}{l}\text { Height }^{[\mathrm{f}]} \\
(\mathrm{nm})\end{array}$ & Morphology ${ }^{[g]}$ \\
\hline $\mathbf{A}_{150} \mathbf{B}_{70}$ & 46.2 & -40.6 & 44 & 0.04 & 32 & 5 & $\mathrm{~S}$ \\
\hline$A_{150} B_{100}$ & 51.2 & -43.5 & 62 & 0.05 & 42 & 9 & $\mathrm{~S}$ \\
\hline$A_{150} B_{150}$ & 59.7 & -45.8 & 83 & 0.05 & 56 & 18 & $\mathrm{~S}$ \\
\hline
\end{tabular}

${ }^{[\mathrm{a}]}$ Composition (A = PAMPS, B = PDAAM; subscript: DP) determined by ${ }^{1} \mathrm{H}$ NMR. ${ }^{[b]}$ Numberaverage molecular weight $\left(\mathrm{M}_{\mathrm{n}}\right)$ determined by ${ }^{1} \mathrm{H}$ NMR. ${ }^{[\mathrm{c}] \zeta}$-potential determined by aqueous electrophoresis. ${ }^{[\mathrm{d}]}$ Mean hydrodynamic diameter $\left(\mathrm{D}_{\mathrm{h}}\right)$ and particle size distribution (PDI) evaluated by DLS. ${ }^{\left[{ }^{e]}\right.}$ Mean diameter $\left(D_{n}\right)$ obtained by TEM statistical analysis. ${ }^{[f]}$ Height evaluated by AFM. ${ }^{[\mathrm{g}]}$ Spherical morphology (S) observed from TEM and AFM images.
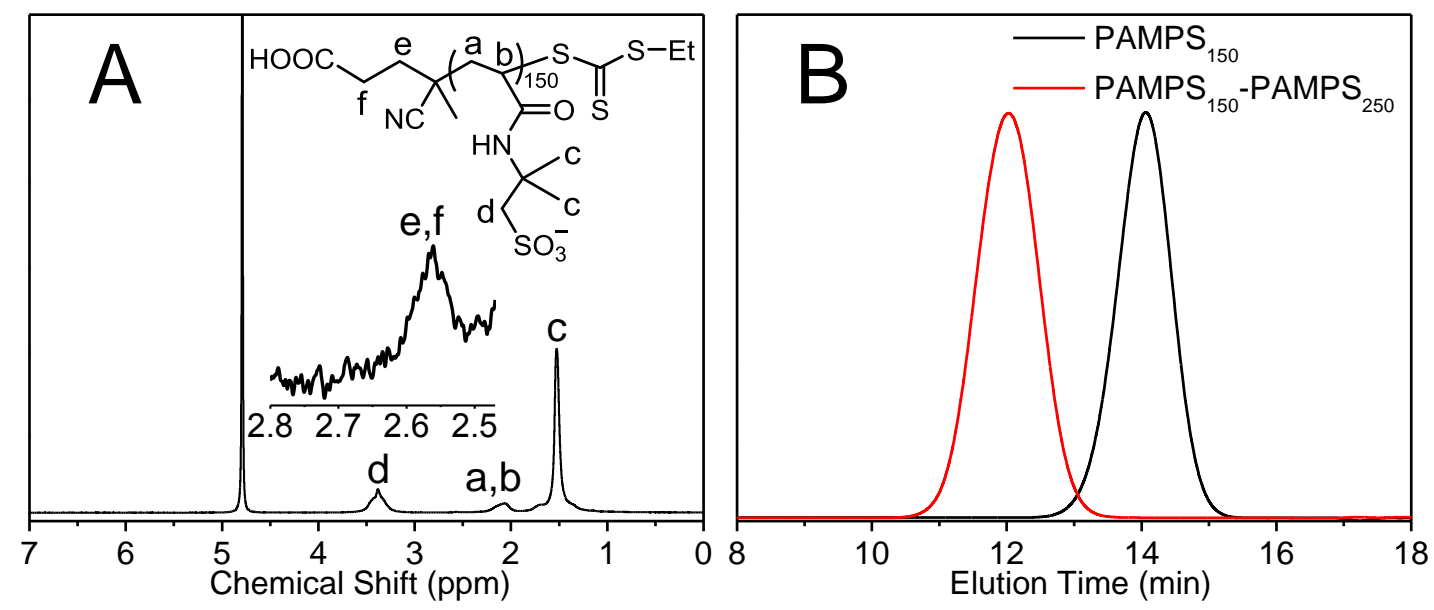

Figure S1. (A) ${ }^{1} \mathrm{H}$ NMR spectrum of PAMPS ${ }_{150}$ macro-CTA in $\mathrm{D}_{2} \mathrm{O}$. (B) A clear shift of the SEC trace upon the chain extension to form a PAMPS $_{150}-$ PAMPS $_{250}$ block copolymer indicates the high fidelity of RAFT chain-ends of PAMPS 150 macro-CTA. 

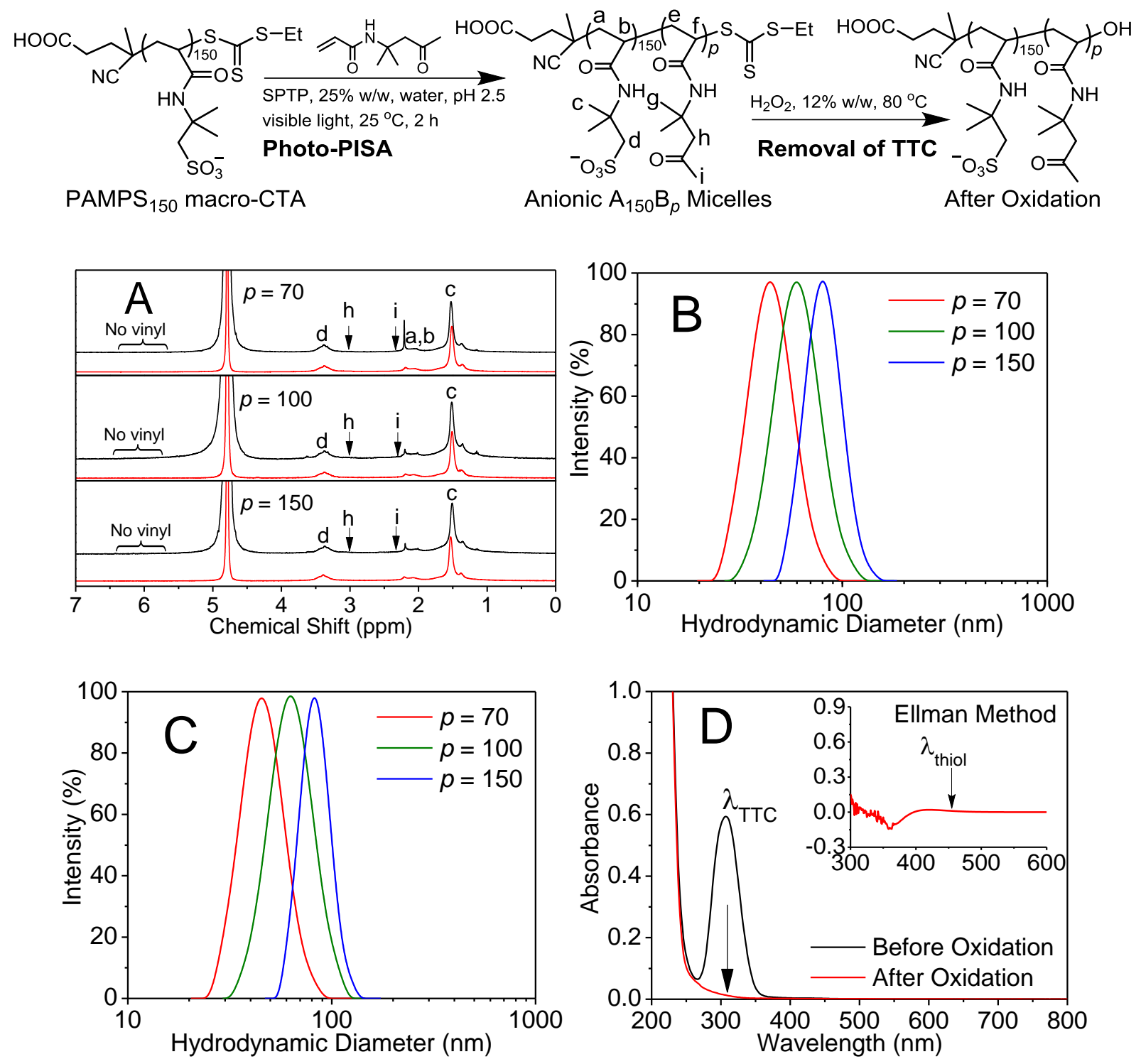

Figure S2. (A) ${ }^{1} \mathrm{H}$ NMR spectra of (black) as-synthesized $\mathrm{A}_{150} \mathrm{~B}_{p}$ anionic micelles and (red) those after removal of RAFT chain-ends (TTC: trithiocarbonate). (B, C) Particle size distributions before (B) and after (C) oxidation reaction determined by DLS. (D) UV-vis spectra of $\mathrm{A}_{150} \mathrm{~B}_{70}$ dispersions before and after oxidation reaction (inset: Ellman result suggests the absence of thiol impurities). 


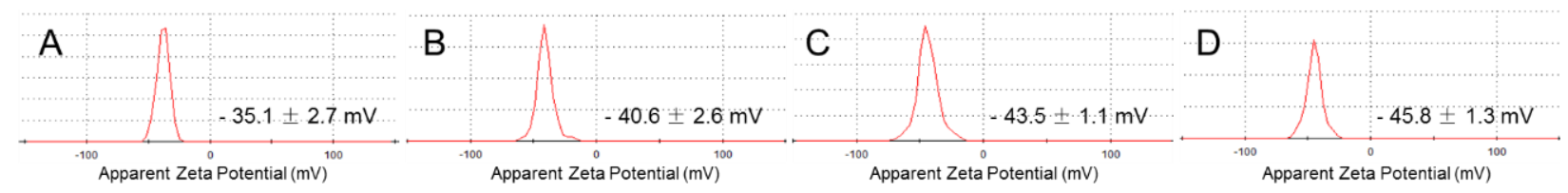

Figure S3. The $\zeta$-potential results of (A) PAMPS 150 and (B-D) anionic micelles of $\mathrm{A}_{150} \mathrm{~B}_{p}$ diblock copolymers at $p=70(\mathrm{~B}), 100(\mathrm{C})$ and $150(\mathrm{D})$, determined at $2.0 \mathrm{mg} / \mathrm{mL}$ in water at $\mathrm{pH} 2.5$.
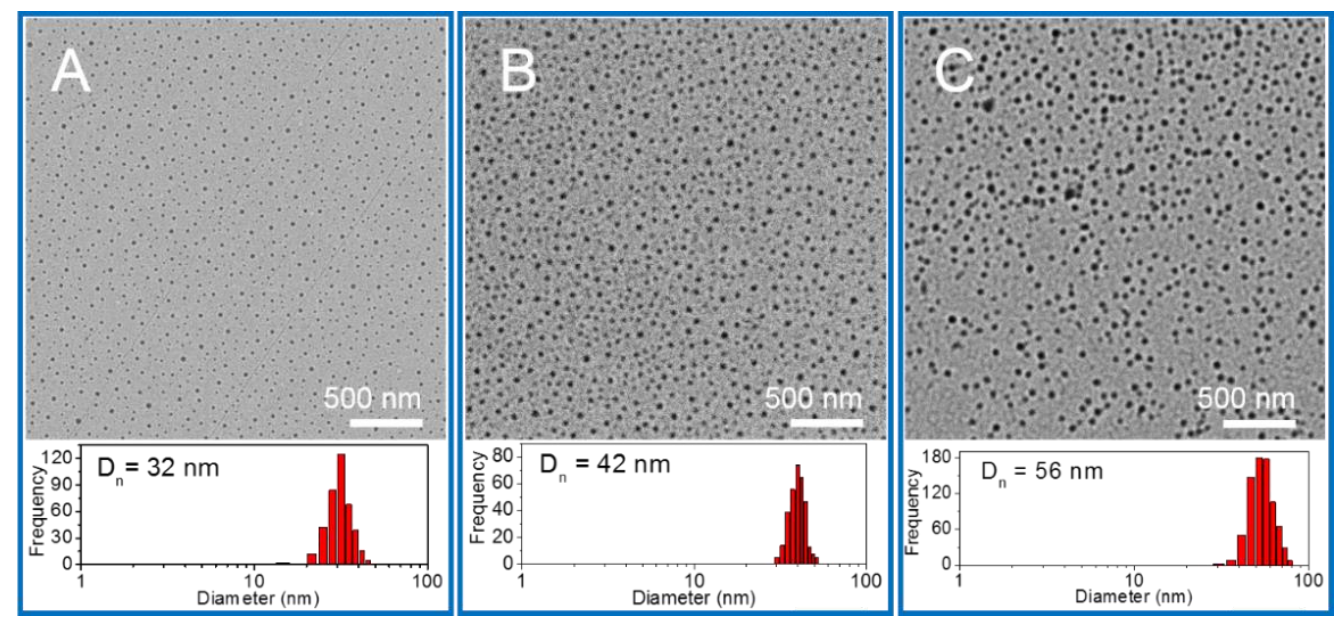

Figure S4. TEM micrographs (top) and statistical analysis results (bottom) of anionic micelles of $\mathrm{A}_{150} \mathrm{~B}_{p}$ diblock copolymers at $p=70(\mathrm{~A}), 100(\mathrm{~B})$ and $150(\mathrm{C})$.
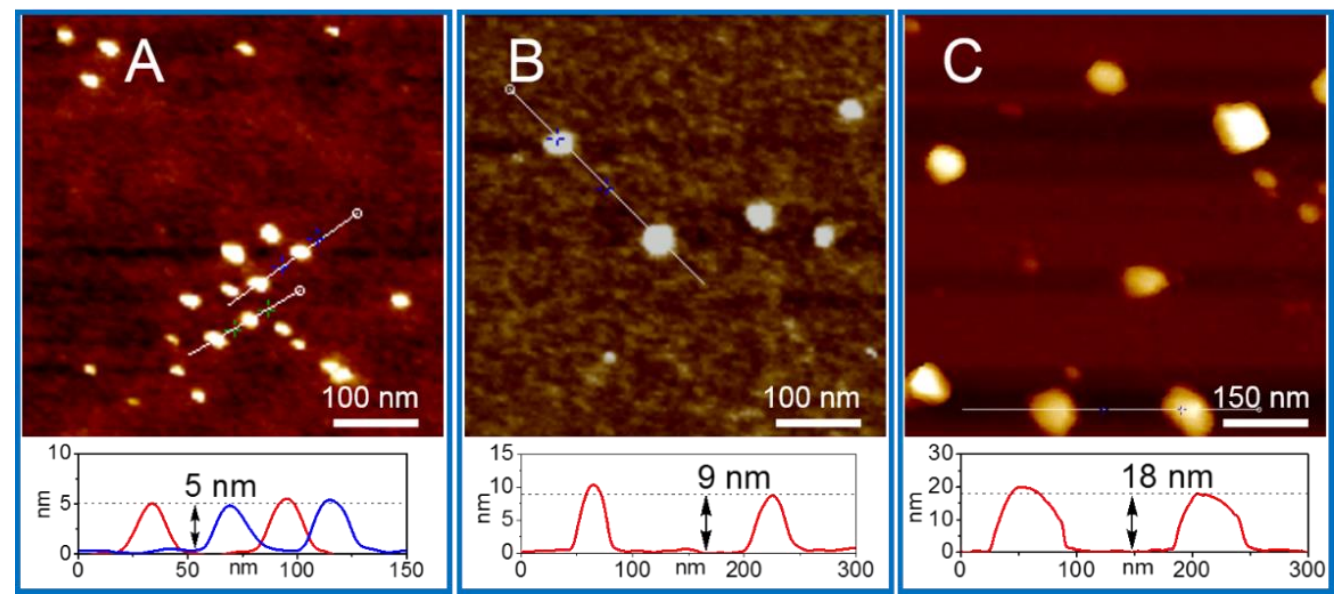

Figure S5. AFM images (top) and cross-section profiles (bottom) of the anionic micelles of $\mathrm{A}_{150} \mathrm{~B}_{p}$ diblock copolymers at $p=70(\mathrm{~A}), 100(\mathrm{~B})$, and 150 (C). 

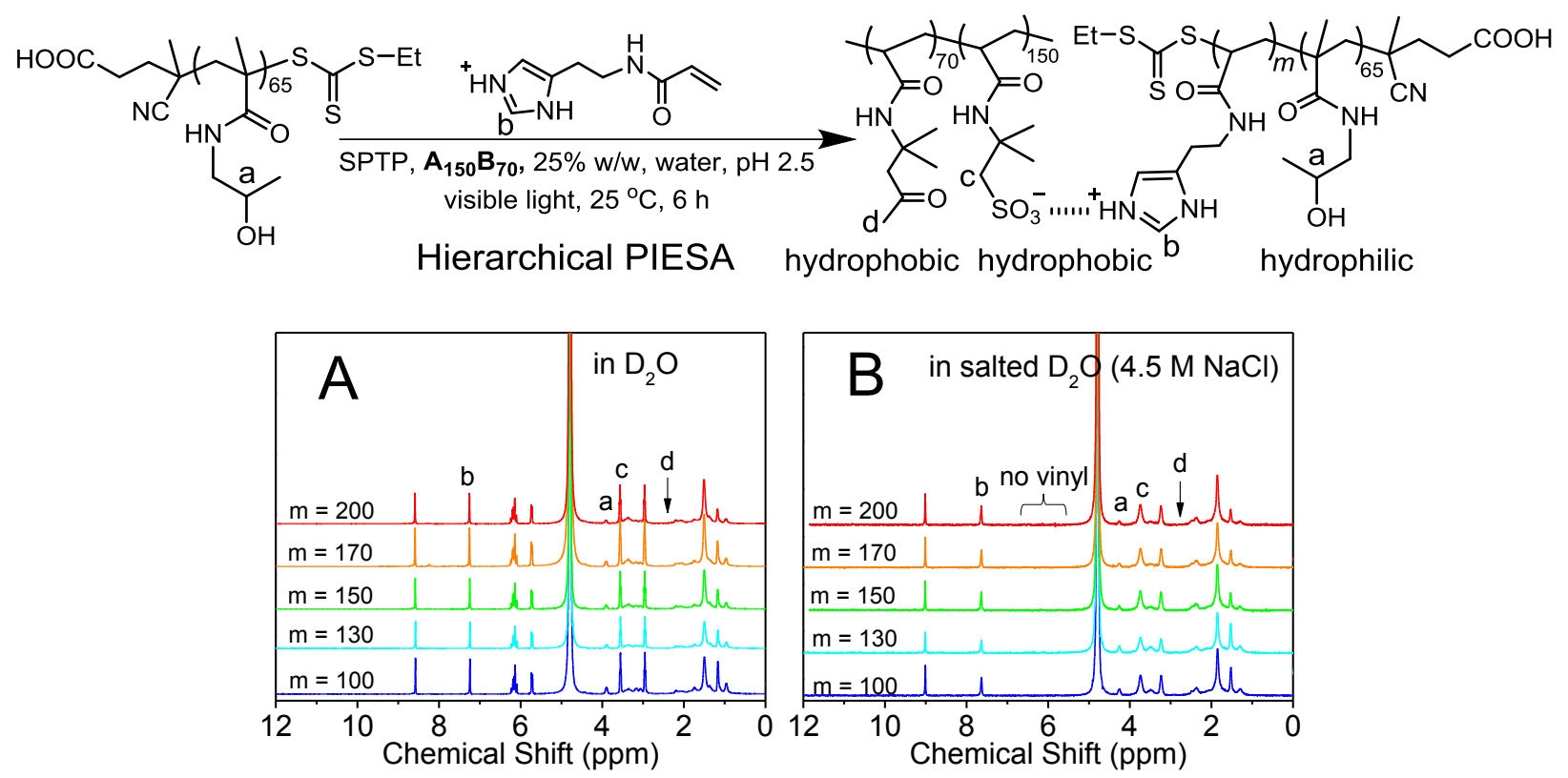

Figure S6. ${ }^{1} \mathrm{H}$ NMR spectra of reaction dispersions before (A) and after (B) hierarchical PIESA using $\mathrm{A}_{150} \mathrm{~B}_{70}$ anionic micelles at labeled $m$ values $\left(m=[\text { HisAM }]_{0} /\left[\mathrm{PHPMA}_{65}\right]_{0}\right)$.

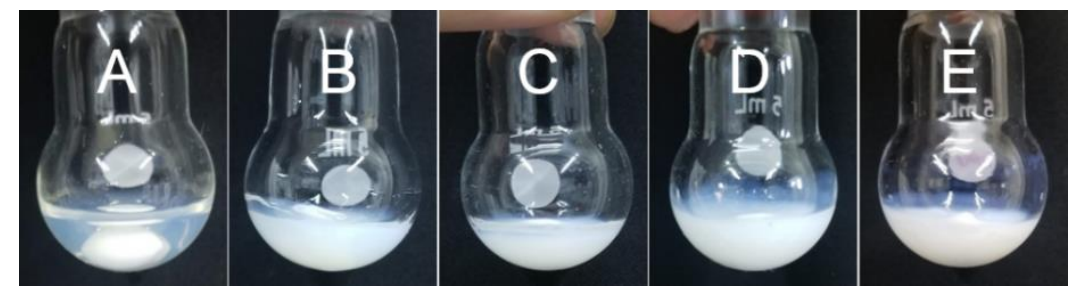

Figure S7. Digital photographs of final dispersions of $\mathrm{A}_{150} \mathrm{~B}_{70} / \mathrm{C}_{65} \mathrm{D}_{m}$ at $m=100$ (A), 130 (B), 150 (C), 170 (D), and 200 (E), synthesized via hierarchical PIESA.

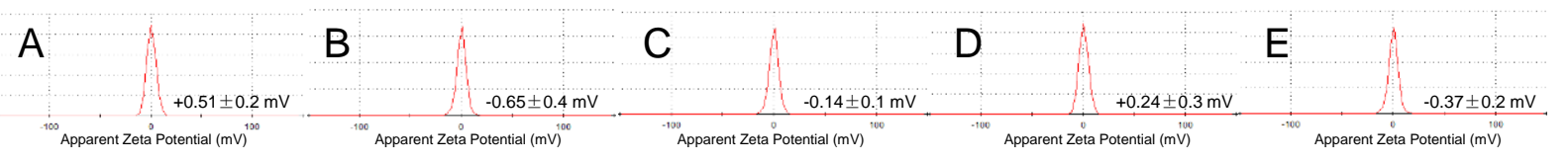

Figure S8. The $\zeta$-potential results of dispersions of $\mathrm{A}_{150} \mathrm{~B}_{70} / \mathrm{C}_{65} \mathrm{D}_{m}$ PICs at $m=100(\mathrm{~A}), 130$ (B), $150(\mathrm{C}), 170(\mathrm{D})$, and $200(\mathrm{E})$. 

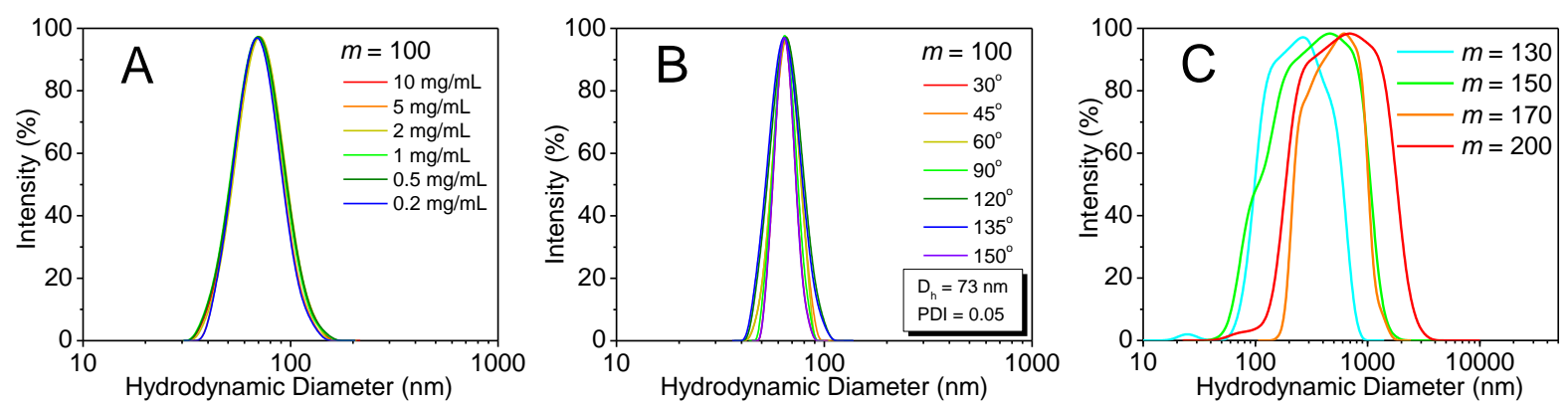

Figure S9. Particle size distributions of $\mathrm{A}_{150} \mathrm{~B}_{70} / \mathrm{C}_{65} \mathrm{D}_{m}$ PICs at (A) $m=100$ at labeled copolymer concentrations determined by DLS measured at $90^{\circ}$, (B) $m=100,2.0 \mathrm{mg} / \mathrm{mL}$, measured at labeled angles, and (C) labeled $m$ values and $2.0 \mathrm{mg} / \mathrm{mL}$ measured at $90^{\circ}$.
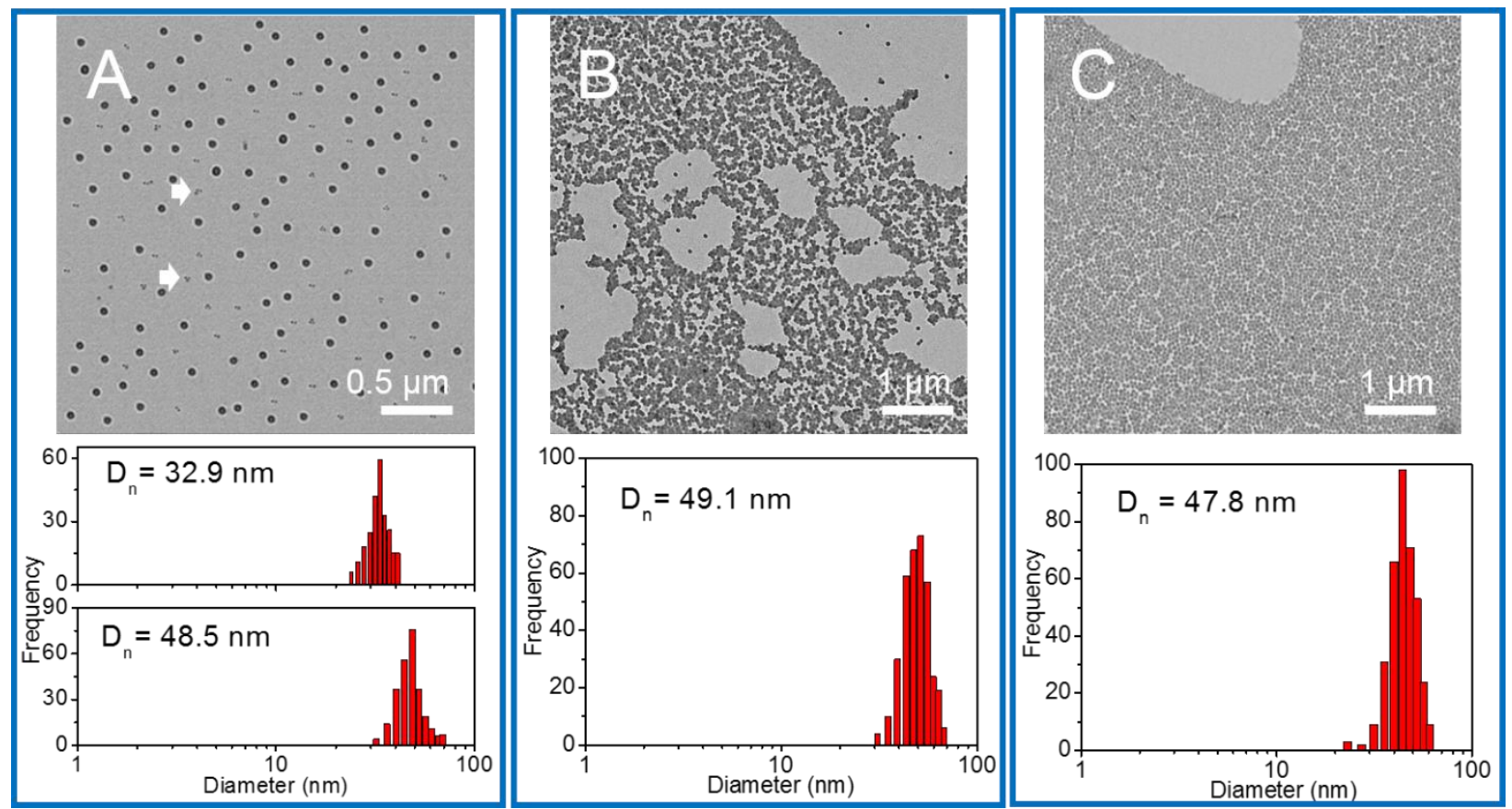

Figure S10. TEM micrographs (top) and statistical results (bottom) of multicompartment micelles of $\mathrm{A}_{150} \mathrm{~B}_{70} / \mathrm{C}_{65} \mathrm{D}_{m}$ at $m=100(\mathrm{~A})$ and those within colloidal nanosheets at $m=130$ (B) and 150 (C). The $\mathrm{D}_{\mathrm{n}}$ of $32.9 \mathrm{~nm}$ was evaluated for interlinked smaller-size micelles at $m=100$ (A, arrows). 

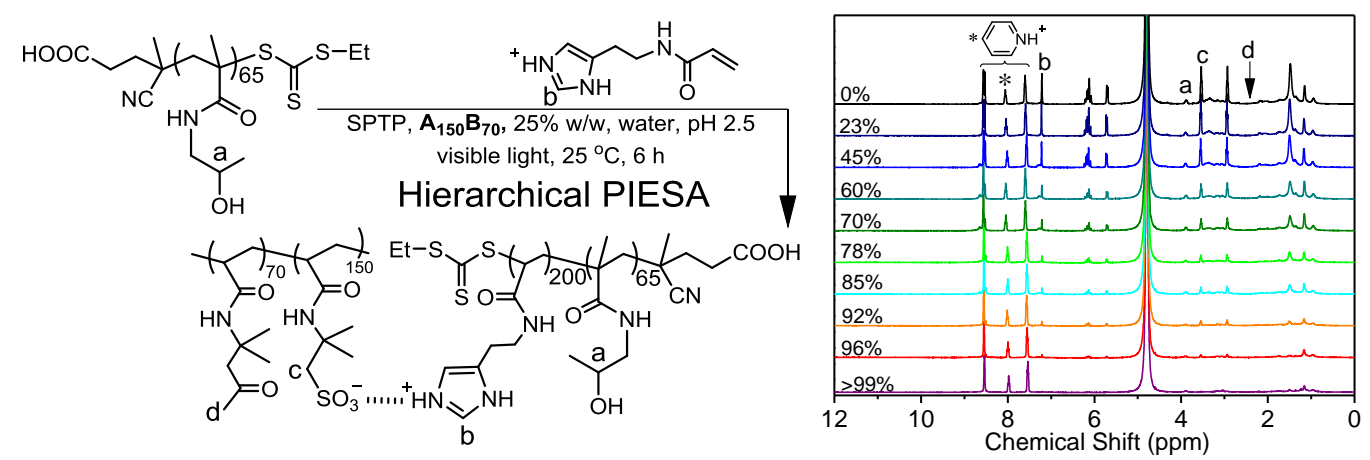

Figure S11. ${ }^{1} \mathrm{H}$ NMR spectrum evolution of the dispersion of hierarchical PIESA at $m=200$ shown in left scheme to labeled conversions, in which pyridine was added as external standard to determine the monomer conversion and the degrees of dehydration of ionic segments.

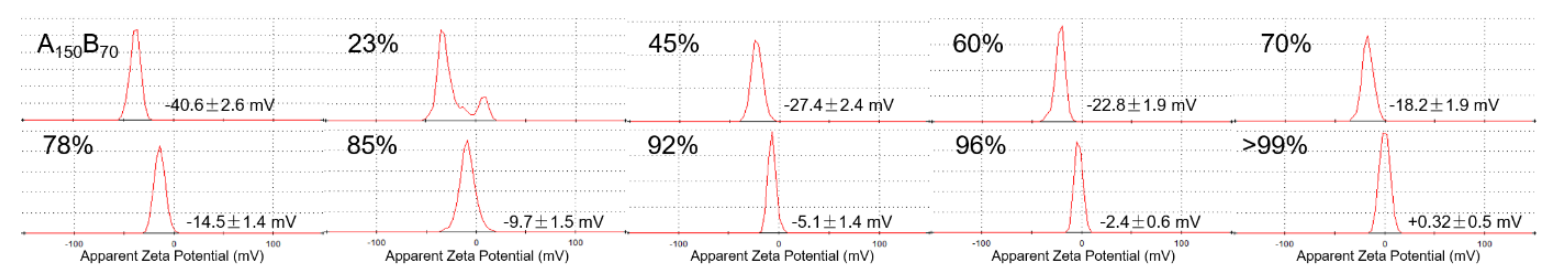

Figure S12. Evolution of $\zeta$-potential of PIC particles formed via hierarchical PIESA at $m=200$ to labeled conversions.
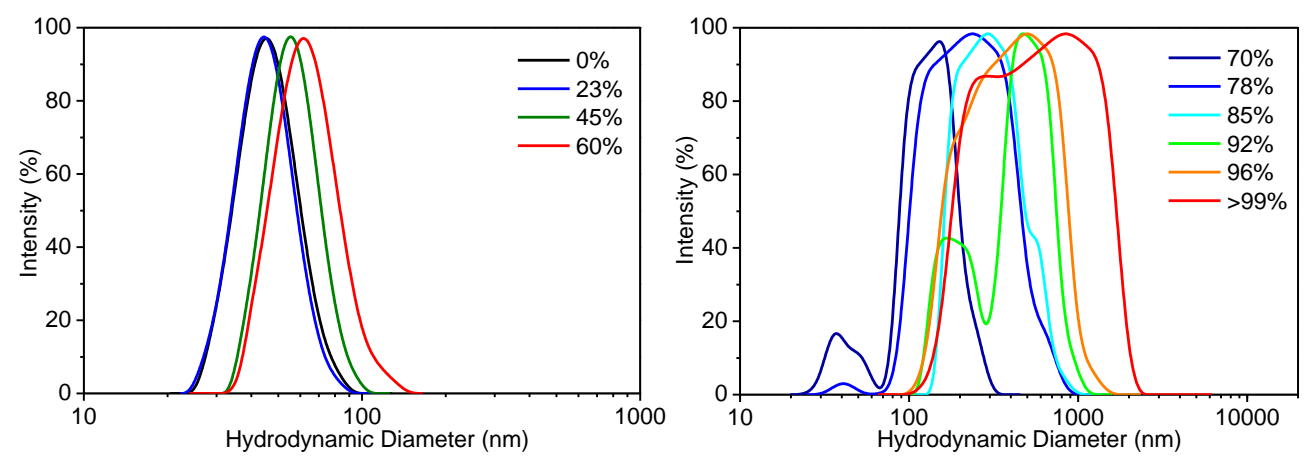

Figure S13. Evolution of particle size distribution of PICs formed via hierarchical PIESA at $m=$ 200 to labeled conversions as determined by DLS studies. 

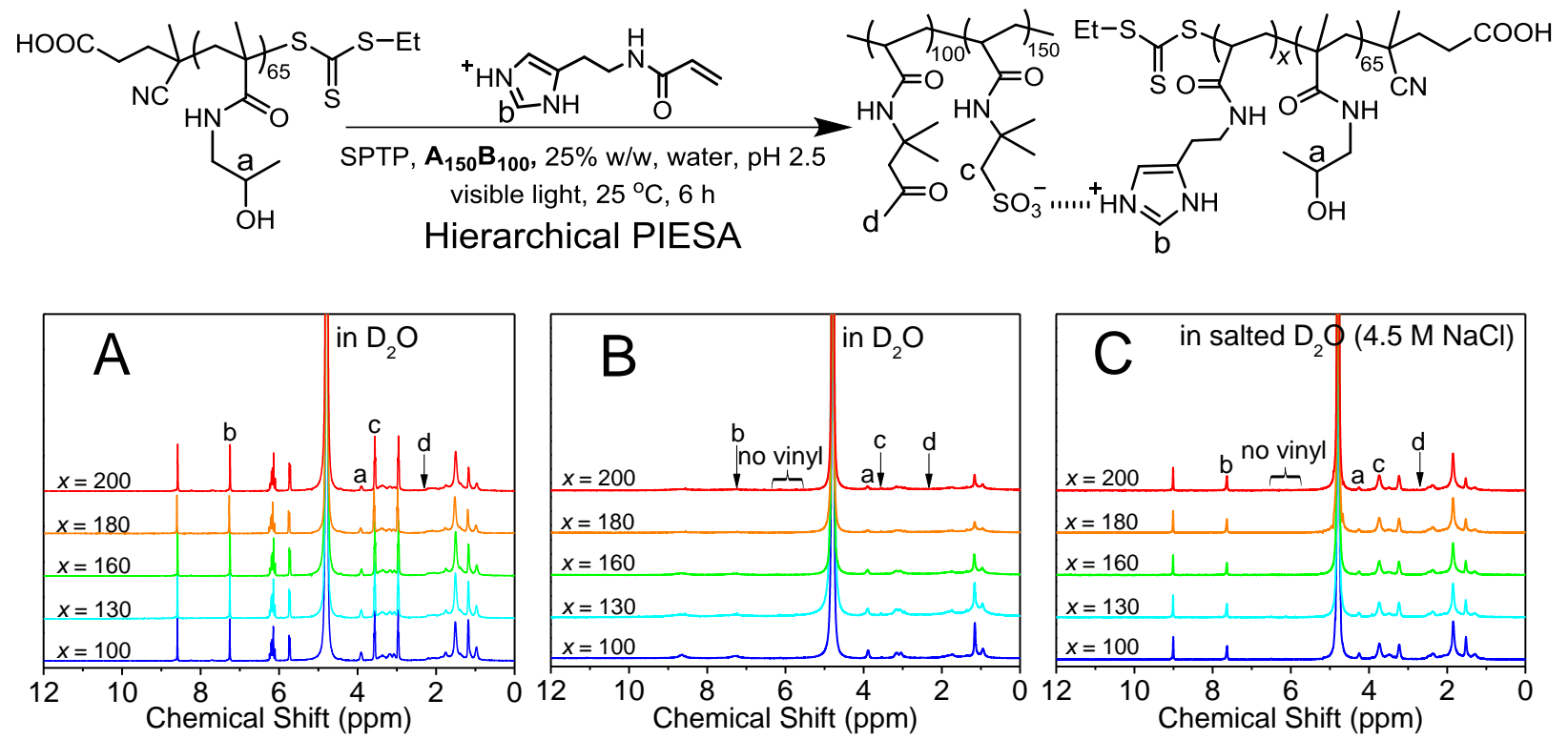

Figure S14. ${ }^{1} \mathrm{H}$ NMR spectra of dispersions before (A) and after (B, C) hierarchical PIESA using $\mathrm{A}_{150} \mathrm{~B}_{100}$ anionic micelles at labeled $x$ values $\left(x=[\mathrm{HisAM}]_{0} /\left[\mathrm{PHPMA}_{65}\right]_{0}\right)$.
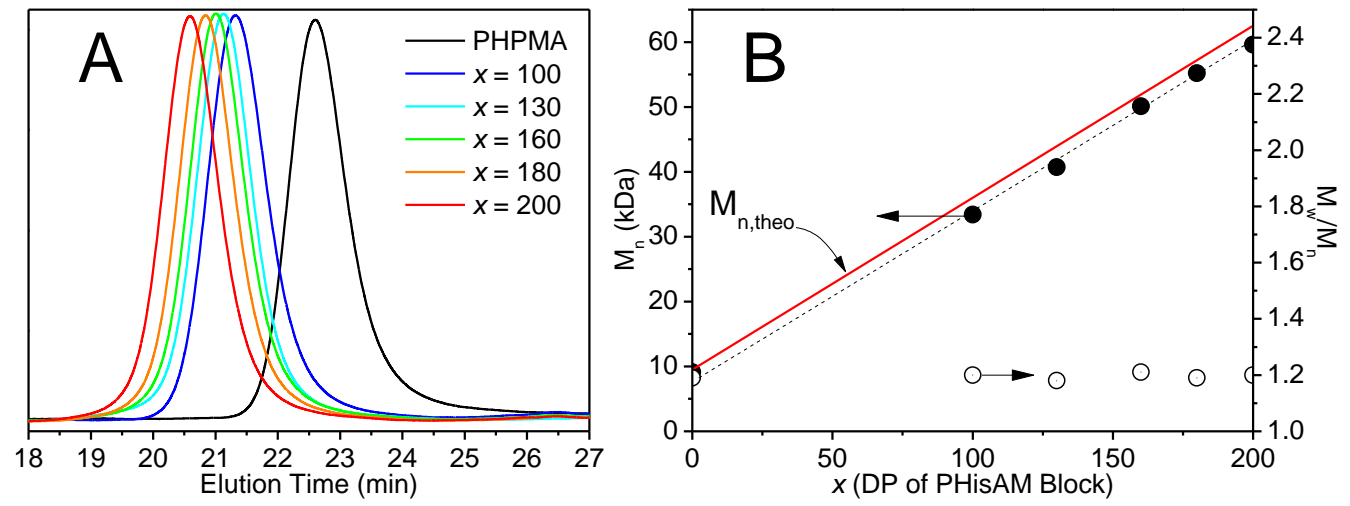

Figure S15. (A) SEC traces of $C_{65} D_{x}$ diblock copolymers at labeled $x$ values. (B) $M_{n}$ and $M_{w} / M_{n}$ versus $x$, the theoretical molecular weight $\left(\mathrm{M}_{\mathrm{n}, \text { theo }}\right)$ was calculated by $\mathrm{M}_{\mathrm{n}, \text { theo }}=\mathrm{M}_{\text {PHPMA }}+x \times \mathrm{M}_{\text {HisAM }}$ (MPHPMA and $\mathrm{M}_{\text {HisAM }}$ are the molecular weights of PHPMA macro-CTA and HisAM monomer). 

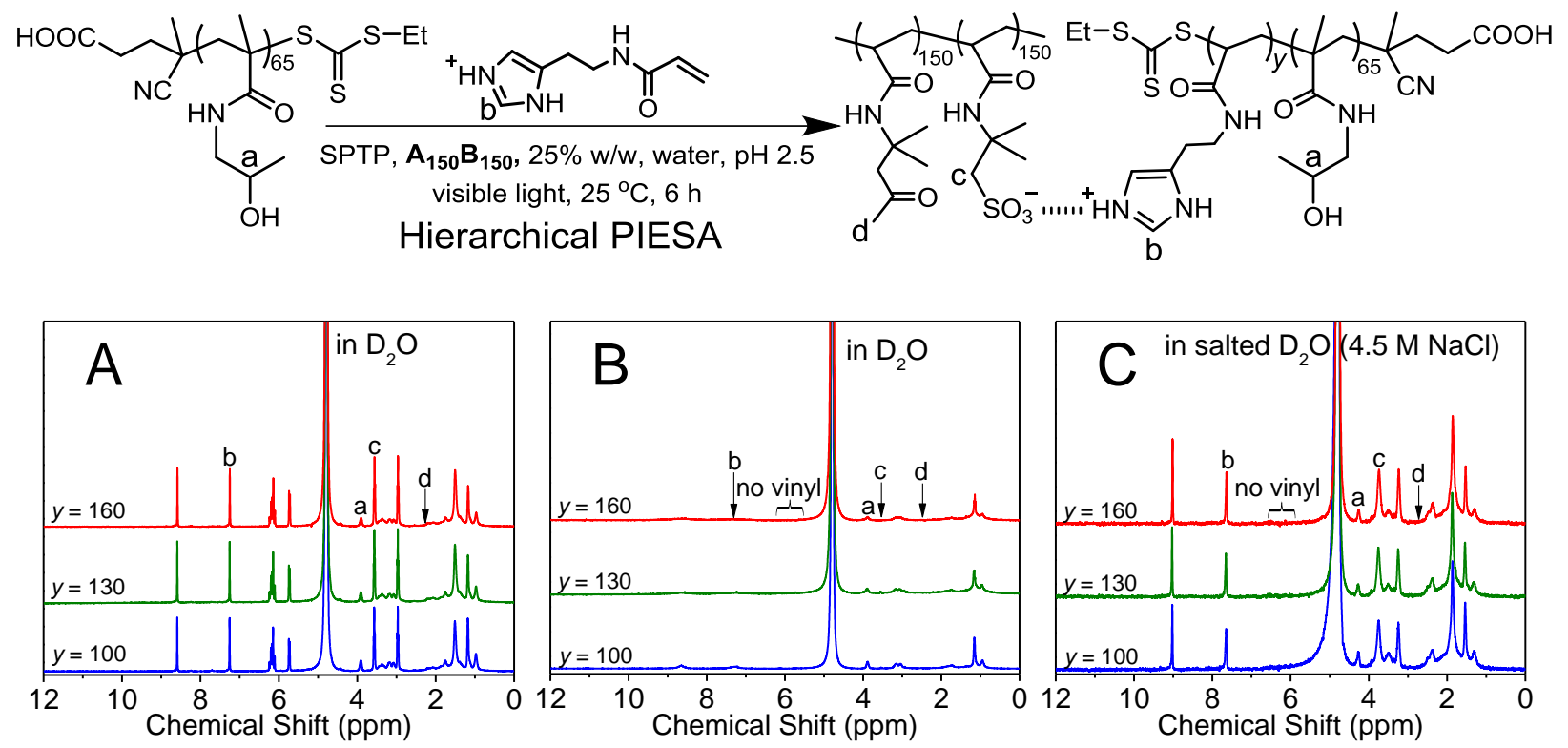

Figure S16. ${ }^{1} \mathrm{H}$ NMR spectra of dispersions before $(\mathrm{A})$ and after $(\mathrm{B}, \mathrm{C})$ hierarchical PIESA using $\mathrm{A}_{150} \mathrm{~B}_{150}$ anionic micelles at labeled $y$ values $\left(y=[\text { HisAM }]_{0} /\left[\mathrm{PHPMA}_{65}\right]_{0}\right)$.
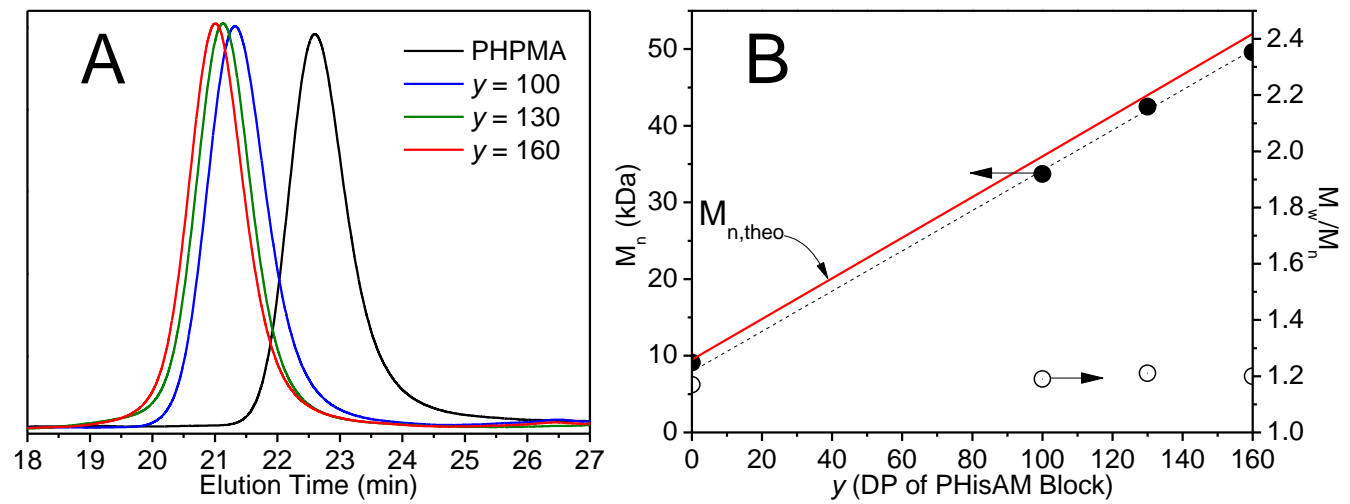

Figure S17. (A) SEC traces of $\mathrm{C}_{65} \mathrm{D}_{y}$ diblock copolymers at labeled $y$ values. (B) $\mathrm{M}_{\mathrm{n}}$ and $\mathrm{M}_{\mathrm{w}} / \mathrm{M}_{\mathrm{n}}$ versus $y$, where the theoretical molecular weight was calculated by $\mathrm{M}_{\mathrm{n} \text {,theo }}=\mathrm{M}_{\mathrm{PHPMA}}+y \times \mathrm{M}_{\mathrm{HisAM}}$ (MPHPMA and M 


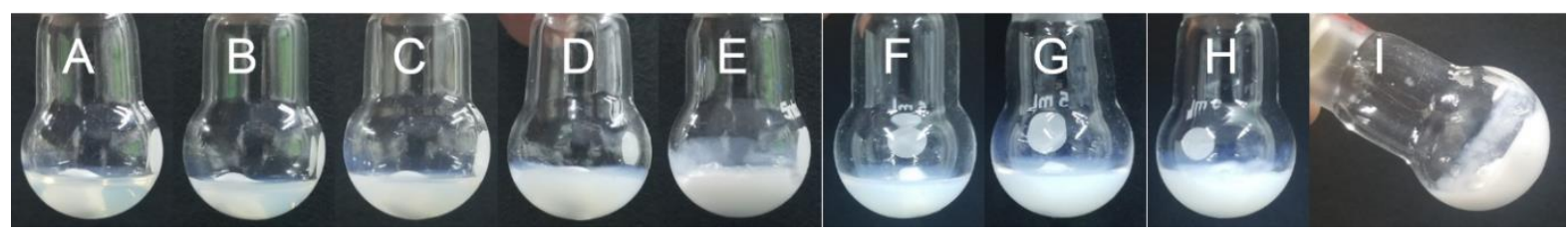

Figure S18. Digital photographs of final dispersions of $\mathrm{A}_{150} \mathrm{~B}_{100} / \mathrm{C}_{65} \mathrm{D}_{x}$ at $x=100(\mathrm{~A}), 130$ (B), $160(\mathrm{C}), 180(\mathrm{D})$, and $200(\mathrm{E}) ; \mathrm{A}_{150} \mathrm{~B}_{150} / \mathrm{C}_{65} \mathrm{D}_{y}$ at $y=100(\mathrm{~F}), 130(\mathrm{G}), 160(\mathrm{H})$, and $180(\mathrm{I})$.

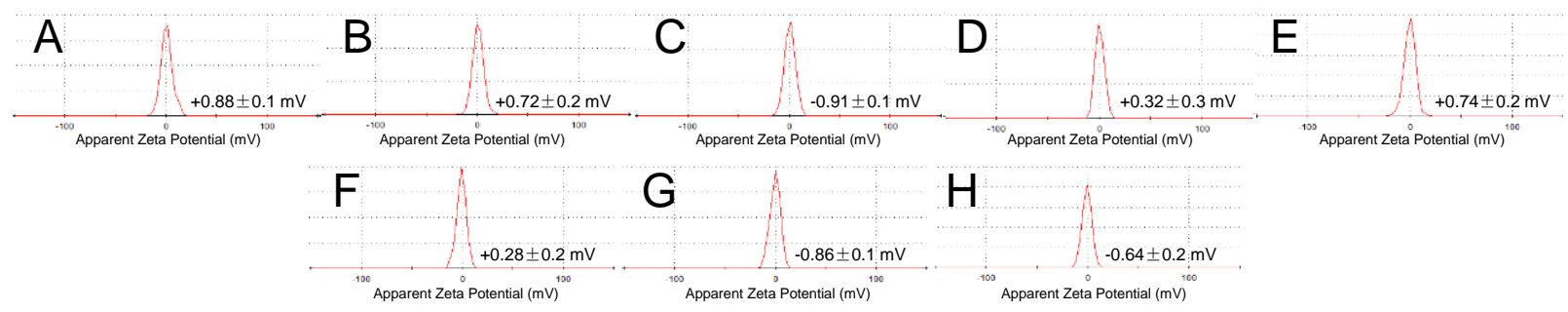

Figure S19. The $\zeta$-potential results of $\mathrm{A}_{150} \mathrm{~B}_{100} / \mathrm{C}_{65} \mathrm{D}_{x}$ PICs at $x=100$ (A), 130 (B), 160 (C), 180 (D), and $200(\mathrm{E}) ; \mathrm{A}_{150} \mathrm{~B}_{150} / \mathrm{C}_{65} \mathrm{D}_{y}$ at $y=100(\mathrm{~F}), 130(\mathrm{G})$, and $160(\mathrm{H})$.
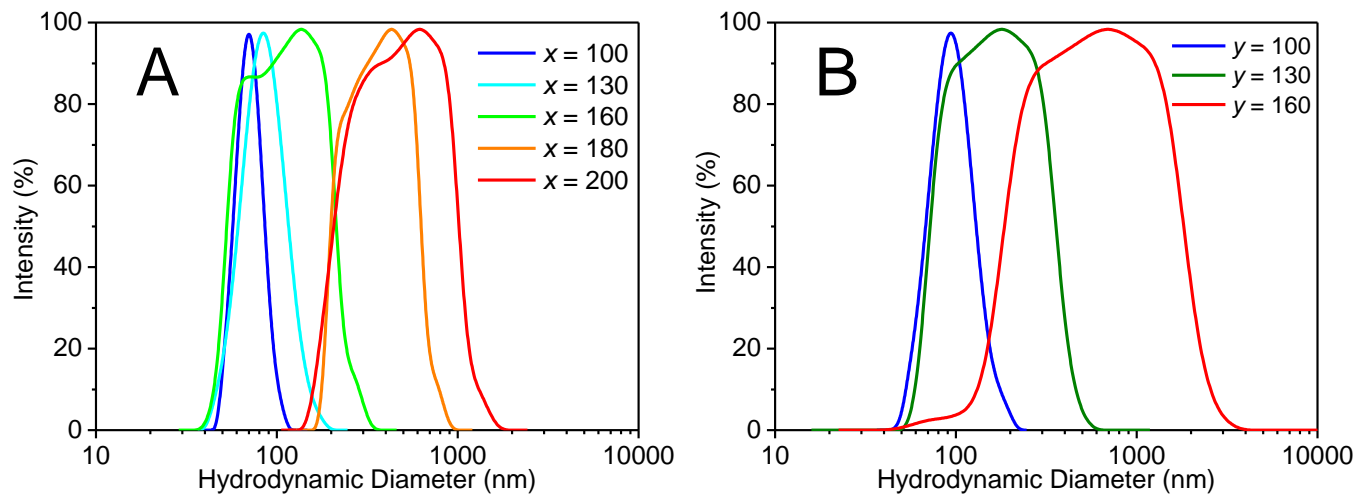

Figure S20. Particle size distributions of the (A) $\mathrm{A}_{150} \mathrm{~B}_{100} / \mathrm{C}_{65} \mathrm{D}_{x}$ and (B) $\mathrm{A}_{150} \mathrm{~B}_{150} / \mathrm{C}_{65} \mathrm{D}_{y}$ PICs at labeled $x$ or $y$ values as determined by DLS studies. 


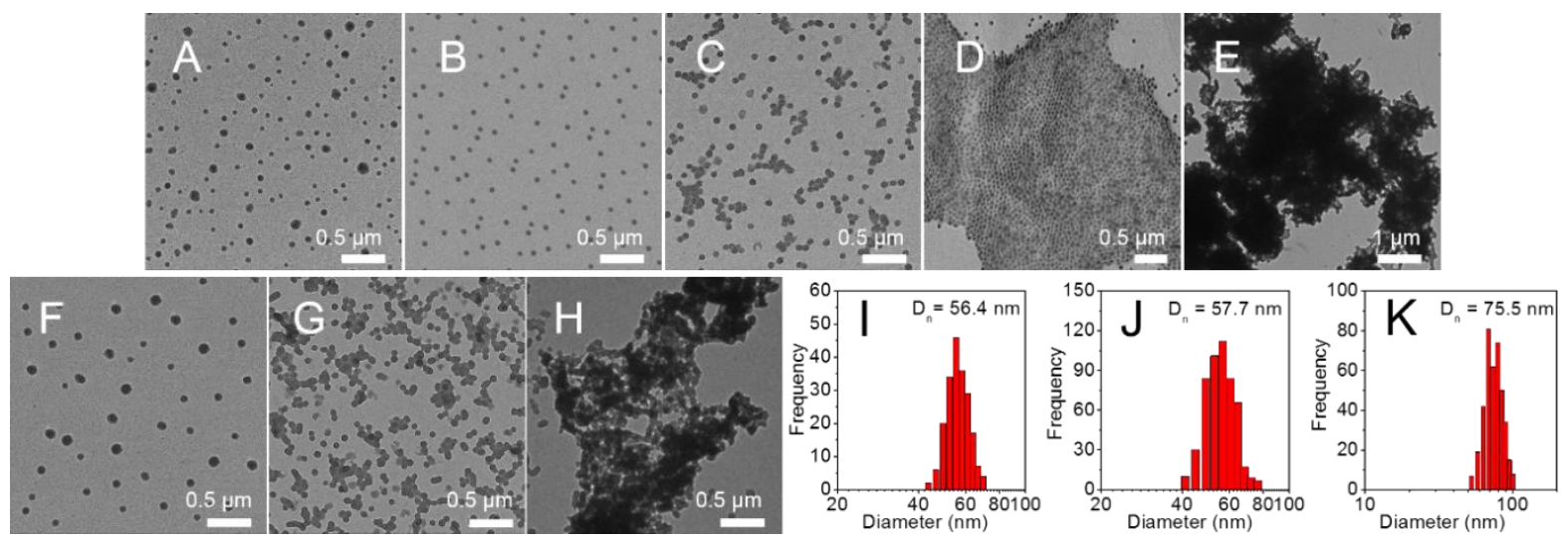

Figure S21. (A - H) TEM micrographs of multicompartment PIC micelles of $\mathrm{A}_{150} \mathrm{~B}_{100} / \mathrm{C}_{65} \mathrm{D}_{x}$ at $x$

$=100(\mathrm{~A}), 130(\mathrm{~B}), 160(\mathrm{C}), 180(\mathrm{D}), 200(\mathrm{E}) ; \mathrm{A}_{150} \mathrm{~B}_{150} / \mathrm{C}_{65} \mathrm{D}_{y}$ at $y=100(\mathrm{~F}), 130(\mathrm{G})$ and $160(\mathrm{H})$.

(I - J) TEM statistical analysis results of the multicompartment PIC micelles of $\mathrm{A}_{150} \mathrm{~B}_{100} / \mathrm{C}_{65} \mathrm{D}_{x}$ at

$x=130(\mathrm{I})$ and $160(\mathrm{~J})$, and $\mathrm{A}_{150} \mathrm{~B}_{150} / \mathrm{C}_{65} \mathrm{D}_{y}$ at $y=130(\mathrm{~K})$.

\section{Reference}

(1) Cai, M.; Ding, Y.; Wang, L.; Huang, L.; Lu, X.; Cai, Y. Synthesis of One-Component Nanostructured Polyion Complexes via Polymerization-Induced Electrostatic Self-Assembly. ACS Macro Lett. 2018, 7, 208-212.

(2) Tong, J.; Shi, Y.; Liu, G.; Huang, T.; Xu, N.; Zhu, Z.; Cai, Y. Visible Light Mediated Fast Iterative RAFT Synthesis of Amino-Based Reactive Copolymers in Water at 20 degrees C. Macromol. Rapid Commun. 2013, 34, 1827-1832.

(3) Xu, X. W.; Smith, A. E.; Kirkland, S. E.; McCormick, C. L. Aqueous RAFT Synthesis of pHResponsive Triblock Copolymer mPEO-PAPMA-PDPAEMA and Formation of Shell CrossLinked Micelles. Macromolecules 2008, 41, 8429-8435.

(4) Ding, Y.; Cai, M.; Cui, Z. G.; Huang, L. L.; Wang, L.; Lu, X. H.; Cai, Y. L. Synthesis of LowDimensional Polyion Complex Nanomaterials via Polymerization-Induced Electrostatic SelfAssembly. Angew. Chem., Int. Ed. 2018, 57, 1053-1056.

(5) Jesson, C. P.; Pearce, C. M.; Simon, H.; Werner, A.; Cunningham, V. J.; Lovett, J. R.; Smallridge, M. J.; Warren, N. J.; Armes, S. P. H2O2 Enables Convenient Removal of RAFT EndGroups from Block Copolymer Nano-Objects Prepared via Polymerization-Induced SelfAssembly in Water. Macromolecules 2017, 50, 182-191.

(6) Qiu, X. P.; Winnik, F. M. Facile and Efficient One-Pot Transformation of RAFT Polymer End Groups via a Mild Aminolysis/Michael Addition Sequence. Macromol. Rapid Commun. 2006, 27, 1648-1653. 